\title{
Relação Contratual entre Distribuidor e Revendedor de Gás Liquefeito de Petróleo (GLP): Estudo de Caso para o Mercado de João Pessoa / PB
}

\section{Contractual Relation between Wholesaler and Retailer of Liquefied Petroleum Gas (LPG): a Case Study of the João Pessoa / PB Market}

\author{
Aldous Pereira Albuquerque* \\ Luciano Menezes Bezerra Sampaio** \\ Felipe Lacerda Diniz Leroy ${ }^{* * *}$
}

Resumo: Este trabalho analisa o mercado de distribuição de gás de cozinha em João Pessoa, mais especificamente, indica uma estrutura de mercado de distribuição e analisa o contrato entre uma distribuidora e uma revendedora, evidenciando quais os impactos para distribuidores, revendedores e consumidor final, após alterações recentes na forma de revenda. Para a análise do contrato entre distribuidor e revendedor, considerou-se um modelo com dois componentes: preço e franquia (dívida, no caso). A relação entre a maior distribuidora e a revendedora líder de João Pessoa revelou um conflito entre as duas partes: a distribuidora tenta capturar os ganhos de revenda com a renegociação da dívida e o revendedor investe em outras iniciativas para não revelar seus verdadeiros ganhos.

Palavras-chave: GLP. Contratos de revenda. Estratégias de mercado.

Abstract: This work analyzes the gas cooking distribution market in João Pessoa, more specifically, indicates a structure of the distribution market and analyzes the contract between a wholesaler and a retailer, showing the impacts for wholesalers, retailers and consumer, after recent changes in the resale format. For the analysis of the contract between a wholesaler and a retailer it was considered a model with two components: price and franchise (debt, in this case). The contractual relation between the greater wholesaler and the principal retailer of João Pessoa showed a conflict between the two parts: the wholesaler tries to capture the resale

\footnotetext{
* Mestre em Economia pela UFPB, Economista e Professor da UFES. E-mail: aldousalbuquerque@ hotmail.com

** Doutor em Economia pela UFPE, Professor do Departamento de Administração da UFRN e do Mestrado em Economia da UFPB. Email: luciano.sampaio@pq.cnpq.br

*** Doutorando em Teoria Econômica pelo Cedeplar - UFMG. Email: fldl@cedeplar.ufmg.br
} 
gains of the retailer through the renegotiation of the retailer's debt and the retailer invests in other initiatives uncovering their real earnings.

Keywords: LPG. Resale contracts. Market strategies.

JEL Classification: D21; L14.

\section{Introdução}

O gás liquefeito de petróleo (GLP), amplamente conhecido como "gás de cozinha”, éum energético utilizado, no Brasil, principalmente para cocção de alimentos, apesar de também ser empregado em outras aplicações como o aquecimento. Mais de 30 milhões de domicílios brasileiros, somados a hospitais, clubes, escolas/creches e estabelecimentos comerciais, como bares e restaurantes, compõem o consumo de GLP no país, sendo este fonte de energia para 95\% da população brasileira.

Após sua produção, o GLPé transportado até as companhias distribuidoras/revendedoras de gás por gasodutos e/ou caminhões. Nelas, o GLP é engarrafado em embalagens distintas, seguindo para o consumo final. A forma de comercialização mais comum é o engarrafamento em botijões de 13 kg (P13), com estimativa do Sindigás (2006) de 99 milhões de botijões P13 em circulação em todo o país correspondendo a uma entrega diária de um milhão e quinhentos mil botijões aos lares brasileiros.

A distribuição de gás de cozinha no Brasil é centralizada em poucas empresas, com quatro delas concentrando 88\% da distribuição do GLP (vendas nacionais), três outras respondendo por 9,4\% e outras sete empresas por 2,6\% do mercado de distribuição. Assim, este setor de distribuição caracteriza-se pela concorrência imperfeita. Estas empresas abastecem os consumidores finais através de mais de 15 mil revendedoras e cerca de 100 mil pontos de venda autorizados (SINDIGÁS, 2005), evidenciado-se a capilaridade da rede de distribuição que atinge todos os municípios brasileiros e tem alcance superior a atendimentos de serviços públicos como água e esgoto.

A relação entre distribuidores e revendedores tem fortes impactos no mercado, interferindo nos preços praticados, e na quantidade a ser ofertada. Os contratos firmados entre as partes e o cumprimento ou não dos mesmos provoca efeitos diretos para o consumidor final. A hipótese deste artigo é que este tipo de contrato pode ser visto como uma franquia no qual a distribuidora financia, cede a marca e instrui os revendedores.

Dnes (1993) realizou um estudo de caso com franquias do Reino Unido, com análise de contratos de franquia de diversos setores, incluindo restaurantes, empresas de prestação de serviços, estacionamentos etc. Ele concluiu que o valor cobrado da franquia pelo franqueador é baseado 
apenas nos seus principais representantes, o que prejudica as pequenas franquias, provocando a saída de muitas do mercado.

Agrawal e Lal (1995) realizaram um estudo dos fatores que influenciam os indivíduos a adquirirem uma franquia e ainda calculou a probabilidade do franqueador monitorar o franqueado, concluindo que em muitos casos os franqueados tornam-se extremamente dependentes dos franqueadores, sem conseguirem o pagamento de suas dívidas.

O objetivo deste trabalho consiste em analisar o mercado de distribuição de gás de cozinha em João Pessoa/PB pela ótica dos modelos de franquia, mais especificamente, investigar o contrato de "franquia" entre uma distribuidora e uma revendedora (líder) do mercado da cidade e suas implicações para o mercado de distribuição da mesma.

Além desta introdução, apresenta-se, na Seção 2, uma breve descrição do mercado de distribuição de GLP em João Pessoa/PB e, em seguida, na Seção 3, o modelo de contrato entre distribuidor e revendedor. Na Seção 4 são expostos os principais resultados e discussão e na Seção 5, as devidas conclusões.

\section{Mercado de Distribuição de GLP em João Pessoa}

Segundo o Instituto Brasileiro de Geografia e Estatística (IBGE, 2005), o número de domicílios particulares permanentes em João Pessoa é de 151.729, resultando numa média de 4,4 habitantes por domicílio. De acordo com o Sindigás, uma família consome em média 1 botijão de GLP P13 a cada 25 dias, ou seja, em um ano, dada a estimativa de domicílios do IBGE, são consumidos aproximadamente 14,6 botijões por família o que resultaria em 2,2 milhões de botijões por ano.

A distribuição dos botijões é realizada por empresas (distribuidoras), pertencentes a grandes marcas nacionais, com destaque para a Nacionalgás que possui a maior parcela, cerca de $65 \%$ do mercado local. Estas distribuidoras são representadas por revendedoras que, por sua vez, abastecem mais de dois mil pontos de venda.

Assim, em 2006, como mostrado na Tabela 1, as principais distribuidoras e seus volumes mensais de vendas em João Pessoa eram: Nacionalgás, aproximadamente $65 \%$ do mercado ou 142.000 botijões de GLP; Novogás, detentora de aproximadamente $15 \%$ do mercado de João Pessoa/PB, correspondente a um volume mensal de vendas de aproximadamente 33.000 botijões de GLP; Ultragaz, a qual detém cerca de $8 \%$ do mercado de distribuição de João Pessoa; Minasgás, cerca de 7\% do mercado de João Pessoa/ PB; Copagás, 3\% do mercado de João Pessoa/PB, com um volume mensal de vendas de aproximadamente 7.000 a 8.000 unidades botijões de GLP.

$\mathrm{Na}$ Tabela 1, discriminam-se as cinco maiores empresas que atuam neste mercado em João Pessoa/PB. 
Tabela 1 - Participação das Principais Distribuidoras no Mercado de João Pessoa e seus Rankings em Nível Nacional

\begin{tabular}{c|c}
\hline Participação do Mercado em João Pessoa/PB & Ranking em nivel Nacional \\
\hline Brasilgás* : $65 \%$ & $4^{\circ}$ \\
\hline Novogás: $15 \%$ & $3^{\circ}$ \\
\hline Ultragaz: $8 \%$ & $1^{\circ}$ \\
\hline Minasgás: $7 \%$ & $2^{\circ}$ \\
\hline Copagás: $3 \%$ & $5^{\circ}$ \\
\hline Outros: $2 \%$ & - \\
\hline
\end{tabular}

* Brasilgás é o nome mantido e conhecido na região local, mas nacionalmente é conhecido por Nacionalgás (será tratada como Nacionalgás no restante do estudo).

Fonte: Elaborada pelos autores de acordo com dados do Sindicato de Revendedores de João Pessoa/PB.

Constata-se que de um número total de 16 empresas atuando no mercado nacional, apenas três (Nacionalgás, Novogás e Ultragaz) concentram cerca de $88 \%$ do mercado em João Pessoa/PB.

As empresas de distribuição em João Pessoa/PB são representadas por revendedoras que abastecem mais de 2.000 pontos de venda. O volume médio negociado de GLP (botijões P13) em João Pessoa/PB está em torno de 220.000 unidades/mês, fornecidos por algumas distribuidoras, com destaque para a Nacionalgás que possui a maior parcela, cerca de $65 \%$ do mercado local.

Observa-se que a Nacionalgás tem a terceira participação nacional no volume de vendas, sendo que, em João Pessoa, ela possui 65\% do mercado e conta ainda com a maior revendedora (revendedora líder) a qual detinha aproximadamente $21 \%$ das vendas da Nacionalgás, o que correspondia a 30.000 unidades de botijões P13 vendidas por mês e a segunda maior revendedora (20.000 unidades de botijões P13 vendidas por mês - 14\% das vendas de GLP da Nacionalgás). A Nacionalgás conta ainda com outras quatro revendedoras, duas com participação aproximada de $8 \%$ de suas vendas de GLP e as demais com volume de vendas mensal de 5.000 unidades de botijões P13 vendidas (aproximadamente 4\% das vendas). Estas seis revendedoras representam, em conjunto, aproximadamente $60 \%$ das vendas da Nacionalgás no mercado de João Pessoa/PB. O restante das vendas é feito por empresas pequenas com um volume médio mensal de vendas em torno de 1.000 a 3.000 unidades.

As demais empresas distribuidoras também têm estrutura de revenda semelhante. A Novogás, por exemplo, conta com dez revendedores, o maior responsável por 14.000 unidades de botijões P13 vendidas por mês - aproximadamente $42 \%$ das vendas de GLP da Novogás; um outro 
com vendas de cerca de 6.000 unidades de botijões P13 por mês; outras duas revendedoras, cujos volumes correspondem a 3.000 e 2.000 por mês e ainda seis revendedoras menores as quais respondem por um volume negociado entre 1.000 e 2.000 unidades de GLP por mês.

A Ultragaz detém cerca de $8 \%$ do mercado de João Pessoa/PB, representando uma quantidade mensal de vendas de aproximadamente 16.000 unidades de botijões de GLP, através de três revendedoras principais que vendem mensalmente, cada uma, um volume em torno de 3.000 unidades. As demais revendedoras da Ultragaz respondem por volume em torno de 1.500 unidades cada uma.

A Minasgás possui em torno de 7\% do mercado de João Pessoa/PB, com um volume mensal de vendas de aproximadamente 16.000 unidades de botijões de GLP com três revendedoras representando-a.

Já a Copagás possui em torno de 3\% do mercado de João Pessoa/PB, com um volume mensal de vendas de aproximadamente 7.500 unidades de botijões de GLP com uma única revendedora representando-a.

\subsection{Reestruturação de uma Empresa Revendedora}

Detalha-se nesta subseção a reestruturação de uma empresa revendedora, no caso a líder de distribuição no mercado de João Pessoa, representante da Novogás. A revendedora (segundo informações obtidas com seu diretor) operava com prejuízo, decorrente de um alto custo em 2004, obrigando-a a adotar medidas para reduzir custos e assim continuar no mercado. A Tabela 2 resume a estrutura da empresa antes e depois da mudança, em 2004 e 2006, respectivamente.

Tabela 2 - Estrutura da Empresa

\begin{tabular}{c|c}
\hline $\mathbf{2 0 0 4}$ & $\mathbf{2 0 0 6}$ \\
\hline 42 Funcionários & 18 Funcionários \\
\hline 12 Caminhões & 4 Caminhões \\
\hline 800 pontos de venda & 200 pontos de venda \\
\hline $\mathbf{N}^{\circ}$ GLP distribuído & $\mathbf{N}^{\circ}$ GLP distribuído \\
\hline $24.500^{*}$ & $30.000^{*}$ \\
\hline
\end{tabular}

* Número Médio mensal.

Fonte: Elaborada pelos autores com os dados fornecidos pela empresa (2006).

O número de funcionários foi reduzido de 42 para 18, ou seja, corte no quadro de funcionários em mais de $50 \%$. O número de caminhões para entrega do produto aos pontos de venda também diminuiu, passando de 12 para 4 . O número de pontos de venda atendido também foi reduzido 
de 800 para 200, ou seja, a estratégia adotada foi a concentração da revenda em um número menor de pontos de venda, reformulando o perfil dos compradores. Em relação às despesas, evidenciam-se as despesas administrativas (fretes, aluguel, manutenção de equipamentos etc.) que representavam aproximadamente $5 \%$ do custo total, despesas financeiras (bancos, encargos), representando 1\% do custo total, despesas comerciais (propaganda), $1 \%$ do custo total, despesas fixas como encargos com pessoal, material de frota (10,34\% do custo total) e despesas variáveis (3\% do custo total). O restante do custo (aproximadamente 79,66\%) refere-se ao custo de compra de GLP que o revendedor possui com seu distribuidor, o qual representará a maior parte do custo total.

A reestruturação representou uma redução de custos de $R \$ 4,10$ por unidade vendida (por botijão P13), em 2004, para $\mathrm{R} \$ 3,10$ por unidade, em 2006, o que significa a retomada do pagamento da dívida da empresa com a Nacionalgás. Segundo o Sinregás (2006), o custo médio de um revendedor em João Pessoa é de aproximadamente $\mathrm{R} \$ 5,00$ por botijão vendido.

Em suma, a revendedora obteve um aumento de eficiência, uma vez que o número médio de GLP vendido por mês passou de 24.500, em 2004, para cerca de 30.000 unidades de P13, em 2006, apesar da redução da estrutura.

Nota-se que a empresa, mesmo apresentando uma política de cortes de custos, conseguiu aumentar suas vendas e concomitantemente concentrálas em um número menor de pontos de venda. Com isso, a revendedora foi capaz de se reestruturar financeiramente melhorando sua capacidade de pagamento, investimentos e vendas. Em resumo, a revendedora apresentou, após a mudança estrutural, menores custos unitários e maiores volume e preços de venda.

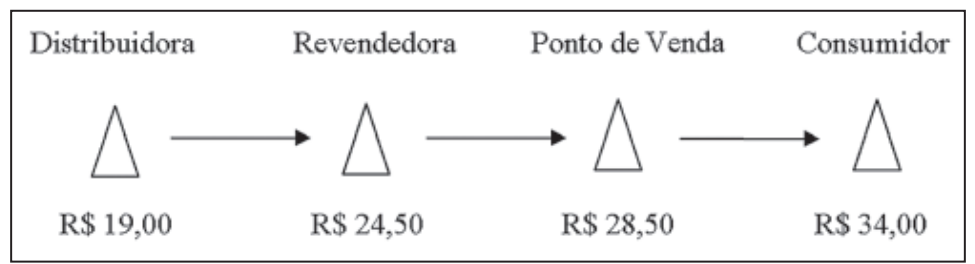

Figura 1 - Estrutura de Margens na Cadeia de Distribuição da Empresa Líder

Fonte: Elaborada pelos autores com base em informações da empresa.

A Figura 1 caracteriza a estrutura de margens da revendedora em maio de 2006. O preço de venda do GLP do distribuidor (no caso, Nacionalgás) é em torno de $\mathrm{R} \$ 19,00$. Adicionando os custos com transporte, a revendedora recebe o produto por $\mathrm{R} \$ 24,50$. A revendedora repassa para os pontos de venda a $\mathrm{R} \$ 28,50$, os quais vendem ao consumidor final por cerca de $\mathrm{R} \$ 34$ reais. 
A revendedora líder e as demais revendedoras atualmente têm três frentes de ação para melhorar seus lucros: tentativa de ampliação da margem de distribuição através de atendimento direto ao consumidor e da realização do próprio frete e combate à inadimplência. A revendedora líder submeteu recentemente um projeto para ampliação do serviço de entrega ao consumidor. Além disso, a empresa passou a realizar o próprio frete, com intuito de aumentar sua margem transportando em veículos próprios (carretas) o GLP adquirido da Nacionalgás nos portos de Cabedelo (PB) e Suape (PE).

Em suma, a empresa operava com prejuízo, em 2004, e passou a operar com lucro em 2006. Parte deste lucro é utilizado para o pagamento da dívida da empresa junto à distribuidora e parte para reinvestimento (nas frentes de ações para aumento do lucro). Até abril de 2008 (prazo estimado para pagamento de sua dívida estabelecido em contrato) a empresa é fiscalizada pela Nacionalgás através da presença de fiscal. Destaca-se que o funcionamento de revendedoras com dívidas contratuais e consequente acompanhamento de interventores é prática corrente no setor de revenda de gás no Brasil.

A dívida contratual garante exclusividade de revenda para a distribuidora. Nestes termos, a distribuidora exclusiva tem maior poder de mercado, uma vez que pode aumentar seu preço cobrado arbitrariamente. A restrição é que o preço cobrado por uma distribuidora para todos os revendedores deve ser o mesmo, contudo a negociação da dívida com cada uma delas pode ser diferente.

Assim, revendedores mais eficientes podem apresentar vantagens sobre aqueles que possuem uma estrutura ineficiente, possibilitando uma margem de lucro melhor, mas também podem ser obrigados a pagar maior parcela da dívida.

É neste contexto que posteriormente analisam-se as estratégias da revendedora líder e da Nacionalgás e as possíveis consequências para o mercado.

\section{Modelo de Contrato entre Distribuidor e Revendedor}

Este modelo apresenta uma empresa que terceiriza a distribuição de seu produto. A empresa cobra uma Franchise fixa de $\mathrm{R} \$ \mathrm{~F}$ e um preço ao revendedor $\left(P^{r e v}\right)$ por unidade do produto. Admitindo-se uma função de demanda linear:

$$
\mathrm{D}\left(\mathrm{p}_{\mathrm{i}}\right)=A_{i}-B_{i} x_{i}
$$

onde $x_{i}$ é a quantidade adquirida pelo revendedor. Seguindo Kreps (1995), para o revendedor maximizar seu lucro, resolve-se: 
$\underset{x_{i}}{\operatorname{MAX} \pi^{r e v}}=x_{i}\left(A_{i}-B_{i} x_{i}\right)-P^{r e v} x_{i}-F_{i}$, rearranjando: $\underset{x_{i}}{\operatorname{MA} \pi^{r e v}}=x_{i} A_{i}-B_{i} x_{i}^{2}-P^{r e v} x_{i}-F_{i}$

A C.P.O é:

$$
A_{i}-2 B_{i} x_{i}-P^{r e v}=0
$$

A quantidade $\left(\mathrm{x}_{\mathrm{i}}\right)$ e o preço que vai ser cobrado dos consumidores $\left(P_{i}^{*}\right)$ encontrados para o revendedor são:

$$
x_{i}^{*}=\frac{A_{i}-P^{r e v}}{2 B_{i}}, \quad P_{i}^{*}=\frac{A_{i}+P^{r e v}}{2}
$$

Contudo, para o revendedor operar é necessário que $\pi^{* \text { rev }} \geq 0$ :

$$
\pi^{r e v}=\frac{\left(A_{i}-P^{r e v}\right)^{2}}{4 B_{i}}-F_{i} \geq 0
$$

Ou seja, o lucro obtido pelo revendedor deve ser maior ou igual a zero, e assim a franquia máxima que pode ser cobrada ao revendedor deve ser tal que:

$$
F_{i} \leq \frac{\left(A_{i}-P^{r e v}\right)^{2}}{4 B_{i}}
$$

A empresa contratante (distribuidor) pretende estabelecer a maior franquia possível e assim, no limite, fazendo o lucro do revendedor igual a zero, impõe:

$$
F_{i}=\frac{\left(A_{i}-P^{r e v}\right)^{2}}{4 B_{i}}
$$

A empresa que contrata a revendedora maximiza seu lucro fazendo:

$$
\begin{aligned}
& \underset{P^{r e v}}{M A X} \pi_{i}=P^{r e v}\left(\frac{A_{i}-P^{r e v}}{2 B_{i}}\right)+\left(\frac{\left(A_{i}-P^{r e v}\right)^{2}}{4 B_{i}}\right)-c\left(\frac{A_{i}-P^{r e v}}{2 B_{i}}\right) \\
& \underset{P^{r e v}}{\operatorname{MAX} \pi_{i}}=\left(P^{r e v}-c\right)\left(\frac{A_{i}-P^{r e v}}{2 B_{i}}\right)+\left(\frac{\left(A_{i}-P^{r e v}\right)^{2}}{4 B_{i}}\right) \\
& \text { C.P.O: }\left(P^{r e v}-c\right)\left(\frac{-1}{2 B_{i}}\right)+1\left(\frac{A_{i}-P^{r e v}}{2 B_{i}}\right)-2\left(\frac{A_{i}-P^{r e v}}{4 B_{i}}\right)=0
\end{aligned}
$$


A solução encontrada é:

$$
\begin{aligned}
& \frac{P^{r e v}-c}{2 B_{i}}=0, \text { que resulta em: } \\
& P^{*^{r e v}}=c
\end{aligned}
$$

A solução é intuitiva. A distribuidora calcula sua franquia de modo que consiga capturar os lucros do revendedor. A variável "c" encontrada representa o custo marginal na equação (6) quando se iguala ao preço que o revendedor paga ao seu distribuidor.

Assim, a empresa contratante cobra a franquia máxima, fixando o preço do produto ao revendedor igual ao custo marginal do mesmo, ou seja, para os revendedores este resultado é semelhante ao de operar em um mercado de concorrência perfeita.

\section{Resultados e Discussão}

A descrição de mercado, discutida em seção anterior, informou que os preços são acordados entre os revendedores, após orientação das empresas distribuidoras. A uniformidade de preços finais ao consumidor de gás de cozinha em João Pessoa/PB e em outras cidades do Nordeste corrobora este fato. Assim, supõe-se que a concorrência se dá via quantidade, visto que os preços são uniformes entre as distribuidoras. Além deste fato, quando empresas produzem uma mercadoria homogênea, é mais natural que a concorrência ocorra por meio da determinação de quantidades em vez de preços.

Para adequação do modelo proposto na Seção 3, considerou-se um distribuidor e o seu principal revendedor (revendedor líder da segunda Seção). A relação entre distribuidor e revendedor ocorre em um ambiente em que a revendedora possui uma dívida com sua distribuidora. Desta forma, além da revendedora ter que pagar seus custos de operação, ela tem um custo adicional (franquia) de operação com a distribuidora.

A composição do mercado atual de GLP em João Pessoa teve como ponto fundamental a "conquista" pela Nacionalgás de revendedores de outras marcas através da proposição de um contrato mais atraente de revenda. O contrato, entre a distribuidora e suas revendedoras, estabelece que o preço de venda do produto para o revendedor $\left(P^{\text {rev }}\right)$ deve ser o mesmo para todos os revendedores. Além disso, os revendedores devem pagar uma parcela da dívida por mês. Ressalta-se que as dívidas são contraídas pelos revendedores no início de suas operações - para aquisição de infraestrutura, insumos e mão de obra para início de funcionamento -, isto é, o endivida- 
mento é quase unânime entre os revendedores. Assim, considerou-se a dívida como sendo uma espécie de franquia adquirida através de um contrato entre o revendedor e seu distribuidor. A dívida (franchise) é paga mensalmente, em geral em prazo pré-estabelecido em contrato, mas com uma parcela mensal que pode variar através de negociação dado o lucro obtido pela revendedora. Lembra-se que a revendedora é fiscalizada pela distribuidora enquanto o pagamento da dívida não for completamente efetuado e assim acompanha a lucratividade da revendedora neste período.

De acordo com o modelo apresentado em 3, a distribuidora (Nacionalgás) cobra a dívida - Franchise $(\mathrm{F})$ - e também cobra um preço $\left(P^{\text {rev }}\right)$ por unidade aos revendedores.

A solução encontrada no modelo apresentado anteriormente foi:

$$
x_{i}^{*}=\frac{A_{i}-P^{r e v}}{2 B_{i}}, P_{i}^{*}=\frac{A_{i}+P^{r e v}}{2}
$$

em que $x_{i}^{*}$ (quantidade que o revendedor compra do distribuidor) e $P_{i}^{*}$ (preço que o revendedor cobra dos consumidores).

Admitindo que estes valores são conhecidos (valores encontrados no mercado de João Pessoa), qual o valor da franquia máxima que o distribuidor pode cobrar de um revendedor?

Sabe-se que para o revendedor operar é necessário que $\pi^{\star \text { rev }} \geq 0$ :

$$
\pi^{r e v}=\frac{\left(A_{i}-P^{r e v}\right)}{4 B_{i}}-F_{i} \geq 0
$$

onde o lucro obtido pelo revendedor menos a parcela de franquia seja maior ou igual a zero. Sendo $F_{i}$ a franquia máxima que pode ser cobrada ao revendedor. O distribuidor vai determinar uma franquia no limite que pode ser representada por:

$$
\pi^{r e v}=R T-C T=0
$$

em que, $\pi^{\text {rev }}=$ Lucro do revendedor.

Assim, o distribuidor vai tentar extrair o máximo possível do lucro do seu revendedor, fazendo com que sua franquia extraia todo o seu excedente.

No mercado em estudo, constatou-se que cada distribuidor destina a um revendedor uma área geográfica para atuar e, portanto, são revendedores exclusivos de cada distribuidor naquela área. Como há um acordo entre os distribuidores para que seus revendedores não forneçam GLP para pontos de vendas de outra distribuidora não há concorrência direta 
entre os revendedores em uma determinada área, pelo menos no sistema de vendas através de pontos.

A concorrência entre os distribuidores é através de incentivos aos revendedores com contratos atraentes. A distribuidora faz com que o revendedor assuma uma dívida e depois tenta tirar o seu excedente.

Assim, a concorrência entre distribuidoras é praticamente na oferta de contratos atrativos aos revendedores que caso passem para outra bandeira (distribuidor) levam consigo todos os seus pontos de venda.

Segundo a revendedora líder, seu preço de compra de GLP é de aproximadamente $\mathrm{R} \$ 25,00$ por unidade (preço pago à distribuidora). Assim, como visto anteriormente, a distribuidora cobra a dívida (franquia) do revendedor de modo que seu lucro seja zero e, portanto, receita total (RT) iguala-se a seu custo total (CT). Sua receita total é dada pelo preço de venda vezes a quantidade, enquanto o custo total é dividido em custo de matéria-prima, custo operacional e mais uma cota de dívida (franquia).

Admitindo-se que em 2004 o volume de vendas era de aproximadamente 24.500 unidades por mês, o lucro mensal da revendedora líder era, na época, em torno de $R \$ 7.166,79$. A dívida paga mensalmente estabelecida em contrato era de $\mathrm{R} \$ 5.000$.

No ano de 2006, esse volume de vendas aumentou passando para aproximadamente 30.000 unidades por mês. Com o aumento da receita e assim do lucro da revendedora, após negociação entre ela e a distribuidora, estabeleceu-se uma ampliação do pagamento mensal de uma para duas parcelas da dívida, cujo novo valor total passou para $\mathrm{R} \$ 10.000$. Assim temos que:

$x_{i}=30.000$ unidades vendidas;

$P^{\text {rev }}=\mathrm{R} \$ 24,20$, preço médio de compra de GLP;

$P_{i}^{*}=\mathrm{R} \$ 27,23$, referente ao preço médio de venda;

$\mathrm{Co}=\mathrm{R} \$ 74.827,44$, referente a custos operacionais sem o custo da matéria-prima.

Substituindo os valores na Equação 1 temos que:

$$
\begin{gathered}
30.000(27,23-24,20)-F-74.827,44=0 \\
F_{i}=16.072,56
\end{gathered}
$$

Observa-se que para o revendedor operar é necessário que $\pi^{* \text { reve }} \geq 0$. No caso apresentado acima, o lucro para o revendedor ainda excede o valor acertado para pagamento mensal da dívida, inclusive possibilitaria o pagamento de até três parcelas da dívida, isto é, seria possível cobrar do revendedor uma "franquia" máxima de 16.072,56. A atual estratégia de cobrança da distribuidora parece inapropriada e vem permitindo que 
a revendedora passe a investir o excedente em outros projetos já mencionados (tele-entrega e realização do próprio frete), os quais geram umlucro ainda maior e permitem a expansão da revendedora no mercado, aumentando a dependência da distribuidora de sua revendedora líder.

Este mecanismo gera consequências para o conjunto de revendedoras representantes da mesma distribuidora e consequentemente para ela própria. A Nacionalgás, para tomar suas decisões de quanto cobrar preço e dívida - usa como parâmetro informações de suas revendedoras (obtidas pelo fiscal que acompanha o funcionamento diário da empresa) e uma revendedora própria que ela mesma opera (com volume de venda mensal de aproximadamente 11.000 unidades). Lembra-se que o preço cobrado é o mesmo para cada uma de suas revendedoras. Assim, para duas revendedoras de mesmo tamanho, com receitas idênticas, aquela que tiver custos marginais menores gera um lucro maior. Portanto, uma política apropriada da distribuidora seria a cobrança da dívida mensal de forma diferenciada, de acordo com os lucros. Por isso a presença do fiscal (gestor da distribuidora) nas revendedoras é essencial, já que é ele que capta as informações de custo das revendedoras.

A Nacionalgás tem interesse particular no acompanhamento da distribuidora líder dado que ela é sua maior revendedora, mas se a Nacionalgás toma seus custos como referência (ou incorpora os mesmos para um cálculo médio das revendedoras) ela pode inviabilizar o pagamento da dívida de suas demais revendedoras uma vez que o lucro que serviria para tanto está sendo empregado no pagamento do preço unitário que excede o custo marginal.

Portanto, existe neste mercado uma tendência de saída de algumas empresas revendedoras (devido à incapacidade de gerar lucros e consequentemente pagar sua dívida) e possivelmente aumento na participação das empresas que apresentarem menores custos por unidade de produção, no caso, a empresa líder.

Uma outra consequência para este mercado é a possibilidade de outras distribuidoras (com maior participação nacional do que a Nacionalgás) tentarem atrair revendedores (inclusive estes que não conseguem pagar suas dívidas) com melhores propostas de contratos, isto é, contratos (leia-se, preço de venda do produto e parcelamento da dívida) que possibilitem a operacionalização e gere possibilidade de expansão do revendedor.

\section{Considerações Finais}

Constatou-se que para os distribuidores atraírem um número maior de revendedores, é preciso elaborar contratos com incentivos aos revendedores, isto é, com preço maior ou igual a seus custos marginais e com 
cobrança da dívida ligada ao desempenho do lucro. A concorrência entre distribuidoras é praticamente na oferta de contratos atrativos aos revendedores. Como os preços cobrados do GLP pelo distribuidor são iguais para todos revendedores, o distribuidor faz discriminação do valor a ser pago da dívida (franquia) de cada revendedor, dívida contraída para aquisição do capital inicial. Sendo assim, o distribuidor pode aumentar a parcela a ser cobrada de franquia sem alterar o preço de venda aos revendedores.

A revendedora líder, estudada em maior detalhe, após sua política de redução de custos, foi capaz de se reestruturar financeiramente e gerar resultados positivos, ou seja, passou a gerar lucros e assim conseguiu arcar com sua dívida contratual e investir em outras iniciativas.

Uma consequência deste sistema de contrato é a constante negociação entre distribuidor e revendedor para estabelecimento do valor do pagamento da parcela da dívida. A distribuidora quer capturar os lucros excedentes da revendedora e esta quer utilizar estes lucros para investir em outras iniciativas (ou seja, outros negócios paralelos) gerando uma ampliação de seus lucros. Â medida que a revendedora vai crescendo a distribuidora quer promover o aumento da parcela a ser paga. Como reação, a revendedora quer investir em outras iniciativas (aumentando seus custos) visando a um maior lucro futuro.

Entre as iniciativas, destacou-se a ampliação do sistema de tele-entrega e a aquisição de veículos próprios (carretas) para realizar o transporte do produto dos portos aos seus depósitos de revenda.

A tendência para as distribuidoras, no longo prazo, é uma maior concorrência com empresas maiores a nível nacional entrando no mercado local através da disputa pelos revendedores, os quais possuem suas redes de pontos de vendas (e cadastro de clientes) e detêm informações sobre o mercado local. Assim, para os revendedores os contratos tendem a ser mais atrativos - preços de recebimento do produto do distribuidor menores e/ou parcelas de dívidas mais baixas - devido a maior concorrência entre as distribuidoras.

Já para os consumidores, a maneira de recebimento do produto é alterada, com a mudança para entrega direta pelos revendedores, proporcionando maior conforto. Sobre o preço final pago pelo consumidor, dois efeitos se contrapõem: aumento devido à concentração de mercado e redução dada à entrega direta (redistribuição da margem do ponto de venda).

A distribuição de GLP em outras cidades brasileiras tem como característica semelhante à apresentada em João Pessoa a sua concentração em grandes firmas nacionais que por sua vez tentam extrair o máximo excedente de suas revendedoras locais através da cobrança de parcela de dívidas e preços unitários médios. Esse sistema de cobrança pode provocar uma 
concentração no mercado de revenda e consequentemente um maior preço do produto ao consumidor final.

\section{Referências}

AGRAWAL, D.; LAL, R. Contractual arrangements in franchising: an empirical investigation. Journal of Marketing Research, v. 32, n.2. p. 213-221, May 1995.

DNES, A. A case-study analysis of franchise contracts. The Journal of Legal Studies, v. 22, n.2. p. 367-393, Jun. 1993.

INSTITUTO BRASILEIRO DE GEOGRAFIA E ESTATÍTICA. Disponível em:< http://www. ibge.gov.br>. Acesso em: 01 maio 2006.

KREPS, D. M. Curso de teoria microeconômica. Madri: McGraw-Hill/Interamericana de España, 1995.

MAS-COLELL, A.; WHINSTON, M. D.; GREEN, J. R. Microeconomic theory. New York: Oxford University Press, 1995.

MINASGÁS. 2006. Disponível em:<http://www.minasgas.com.br > . Acesso em: 01 maio 2006.

SINDIGÁS. GLP no Brasil: 54 anos de História. São Paulo, 1991.

. 2005. Disponível em: <http://www.sindigas.com.br>. Acesso em: 10 abr. 2006.

. 2006. Disponível em: <http://www.sindigas.com.br>. Acesso em: 15 jun. 2006.

SINREGÁS. Sindicato dos Revendedores de Gás de Cozinha de João Pessoa. João Pessoa, 2006.

SIQUEIRA, M. C. Engenheiro Sênior de Desenvolvimento e Qualidade (Cia. Ultragás S.A.). Disponível em: <http://www.ultragas.com.br>. Acesso em: 10 abr. 2006.

VARIAN, H. R. Microeconomic analysis. 3. ed. New York: W.W. Noton E Company, 1992. . Microeconomia: princípios básicos. 6. ed. Rio de Janeiro: Campus, 2003.

Recebido em: 25/10/2007. Aceito em: 03/07/2008. 